\section{Multidisciplinary SCIENTIFIC JOURNAL OF MARITIME RESEARCH}

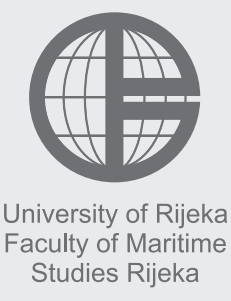

Multidisciplinarni znanstveni časopis POMORSTVO

\title{
The Importance of Harmonizing Working Timetables in Seaport Clusters $^{1}$
}

\author{
Jakov Karmelić, Edvard Tijan \\ University of Rijeka, Faculty of Maritime Studies, Studentska 2, 51000 Rijeka, Croatia, e-mail: etijan@pfri.hr
}

\section{ABSTRACT}

Seaport clusters are complex commercial systems, consisting of a large number of heterogeneous stakeholders. Therefore, it is important to harmonize their business procedures to ensure effectiveness. Harmonization implies the adjustment of differences and inconsistencies among different measurements, methods, procedures, schedules, specifications, or systems to make them uniform or mutually compatible. This paper will particularly research the inconsistencies of working timetables of various seaport cluster stakeholders, which hampers their business flow and seaport effectiveness in general. In order to analyse the inconsistencies of working hours of seaport cluster stakeholders, it was necessary to collect and summarize the working hours of various statutory authorities (government institutions) and service providers (private concessionaires) in the port of Rijeka, Croatia. Data was collected from 14 different stakeholders, and it was evident that working hours' discrepancies exist, manifested by different and uneven periods of daily shifts, daily breaks and periods of regular and overtime work. Service providers have different shifts, and differently defined overtime (and overtime compensation). For the simplicity and transparency of seaport cluster operations, the authors recommend harmonizing the shifts, periods of regular and overtime work, and overtime compensation of all stakeholders, with the ultimate goal to increase the competitiveness of the seaport cluster and the traffic corridor as a whole.
\end{abstract}

\section{ARTICLE INFO}

Preliminary communication

Received 4 March 2018

Accepted 1 June 2018

Key words:

Seaport clusters

Working hours' inconsistencies

Harmonization

\section{Introduction}

Seaport clusters are complex traffic hubs where maritime and land cargo traffic is interwoven. Within the port the cargo is loaded/unloaded from the ships, stored in warehouses, and loaded/unloaded from trucks and trains. In order to receive and dispatch the ship, and to efficiently manipulate the cargo in the ports, numerous specialized seaport stakeholders perform different activities. Those stakeholders can be classified into two main categories: statutory authorities and private companies. The seaport cluster can achieve its goals and be competitive only if all the elements of such a system are connected and synchronized. The quality of seaport services, the efficiency and

1 This work has been financially supported by University of Rijeka under the Faculty of Maritime Studies projects. the prices charged by the port service providers are an important factor for the seaport competitiveness.

Seaport activities are diverse: receiving and dispatching of ships, disembarking, loading and storing of cargo, cargo control and delivery to final recipients, etc. Multiple stakeholders are involved in performing the above mentioned activities, whose heterogeneity can be grouped as follows:

- Stakeholders belonging to the statutory authorities, whose activities fall under the various organizational structures of several different government bodies or ministries. In Croatia, the situation is as follows:

- Port Authority, Harbourmaster office, Dangerous Goods Inspectors (Ministry of Sea, Transport and Infrastructure)

- Sanitary Inspection (Ministry of Health)

- Maritime Border Police (Ministry of the Interior) 
- Customs (Ministry of Finance)

- Phytosanitary and veterinary border inspection (Ministry of Agriculture).

- Private stakeholders/concessionaires and other licensed private operators:

- pilots,

- tugs,

- mooring service,

- ship agents,

- port / terminal operators,

- shippers,

- freight forwarders,

- road carriers

- railway carriers.

Many connections exist among the aforementioned statutory authorities and private concessionaires operating within the seaport and providing their complementary services primarily to ships and cargoes, and indirectly to traders, exporters and cargo recipients. It is necessary to establish an efficient mutual business communication between them, in accordance with the legislation of each country and the set of working procedures in the seaport area. In order to carry out certain tasks on board and in port, simultaneous presence of several different stakeholders is required. If there are bottlenecks preventing the timely presence of these stakeholders, then waiting and work-process stoppages may occur, leading to consequential costs, and worsened perception on the quality of services in port, as well as deterioration of the seaport competitiveness.

In the context of the above mentioned, a research problem can be defined: there are no systematic studies of seaport stakeholder activities with regard to their working timetable, which may have an impact on the business, quality and competitiveness of the seaport cluster. Therefore, the authors deemed necessary to research the work shift periods and breaks, the periods of regular and overtime work as well as the additional costs that individual service providers charge for overtime work. The research was carried out on all stakeholders in Croatian seaport clusters (statutory authorities and private concessionaires/service providers). Accordingly, it was necessary to propose measures for the introduction of harmonized working hours of various seaport cluster stakeholders, thereby improving the quality and competitiveness of the seaport cluster as a whole. The authors will propose measures for the introduction of harmonized working hours of different seaport cluster members, thereby avoiding possible bottlenecks and stoppages, providing greater quality and competitiveness of the port cluster

\section{Literature Review}

Several scientific papers have analyzed the quality of port services. Kolanović lists the most important areas and international authors who have researched port facility quality and who have established models for measuring port facility quality. Different authors took into account dif- ferent dimensions (7 different models) and service quality attributes (30 different attributes), and have also differently pondered the importance of the particular dimension and attribute of the seaport service. For example, reliability in some models is of the utmost importance, while in other models its importance is only in the sixth place [3].

Bendekovic et al. stated that the quality of seaport services, customer satisfaction and port competitiveness depend on the following set of factors: transport policy and regulation, economic conditions, education, technology, security, energy and the environment. Furthermore, they concluded that seaport service quality and port competitiveness play a key role in the seaport development process irrespective of the characteristics of the seaport [2].

Batur and Nikolic stated that some of the major challenges imposed on ports include faster handling of freight, which implies adequate and efficient transhipment equipment, a reduction of time spent in the port, adequate storage capacity and good traffic links to their hinterland [1].

Several authors researched the criterion by which shippers choose a single port. Zanne et al. cite the following most important criteria: port infrastructure and equipment, efficiency, port service frequency, port position, hinterland connection, port costs and reputation [5].

According to UNCTAD, the three main criteria according to which shipping companies decide which ports are to be used are: geographic position in relation to global grids of liner services, amount of cargo that can be expected through individual ports (hinterland) and port costs, service quality and infrastructure [4].

Based on available literature and research on port service quality management, as well as the research of port selection choices by shippers and ship-owners, it can be concluded that several authors cite various models and attributes for measuring the quality of port services and that great emphasis is placed on infrastructural and supra-structural factors, and less on analysis and recommendations for the integrated performance of all service providers in the port, including all state administrative bodies, as well as private concessionaires and other port service providers.

Authors were unable to find the adequate references in the available literature regarding the above mentioned issues (working timetable analysis of different stakeholders in seaport clusters, durations of shifts and breaks, duration of regular time vs. overtime, as well as the additional fees that individual service providers charge to users for overtime work), and consequently, the adverse effects on the competitiveness of the seaport cluster. Therefore, it can be concluded that there is a theoretical and practical justification of the research carried out in this article.

\section{Research Methods}

For the purpose of this research, the usual methodological instruments were used: available documentation and bibliography, scientific articles and other sources from databases and websites, data from the statutory authori- 
ties and private concessionaires in the seaport cluster, and survey.

Significant and valuable information was collected during the discussion held in the Croatian Chamber of Commerce - Regional Chamber in Rijeka, in which the authors participated actively, authors' personal contacts with representatives of business entities involved in this research, as well as many years of experience in shipping companies, the maritime agency and the University.

\section{Basic Operations of Seaport Cluster Stakeholders}

In order to describe the seaport organization and procedures, Figure 1 shows the seaport cluster stakeholders and communication links between them. A vessel was placed at the source, because only after its arrival in the seaport and the start of cargo manipulation, the stakeholders will perform their business roles.

For the reception of the vessel in the seaport, a ship agent (who previously entered the required information into the maritime information system, announced the arrival of the vessel and cargo to the Terminal and coordinates the ship's commercial operations) is engaged, and the Port Authority (Vessel Traffic Service), pilots, tugs and mooring service. Pilots, tugs and mooring service companies must be very well coordinated as they jointly participate in the manoeuvring, berthing and mooring of the vessel.

After the vessel is berthed alongside, the ship agent coordinates the boarding of statutory authorities' representatives (Harbour master, Maritime Police, Customs, Health and Sanitary Authority and the Port Facility Security officer), who after the inspection and check of the ship's documents will grant (or not grant) a permit to start the commercial operations. Only timely and coordinated arrival of all stakeholders aboard a vessel will enable a timely permit to start commercial operations, preventing the idle time of port workers.

The port operator performs unloading and loading the cargo from/to a vessel, and stores the cargo in the port. One of the characteristics of the port operator's competitiveness is the productivity of the workforce, therefore any idle time, including waiting for various inspection procedures (boarding control, cargo lashing control etc.) directly reduces the operator's productivity and its competitiveness.

If the cargo is of plant origin, it will be within the Phytosanitary Border Inspection competence, and if the cargo is of animal origin, it will be within the Veterinary Border Inspection competence. In the case that prerequisites for cargo inspection exist (detailed inspection of the goods, X-ray scanning) it will be performed by the Customs. The promptness of these statutory authorities is also an attribute for the seaport cluster competitiveness, in particular because it can be measured and compared with efficiency at other competing seaports.

When the prerequisites for delivering the cargo to the consignee are met, a cargo agent will be engaged to carry out customs import formalities, and freight forwarder will organize land transport operations performed by road hauliers and rail carriers. The cooperation and coordinated action of these stakeholders, together with the port operator (because the cargo is taken over or handed over from/to the port/terminal) is very important because the time it takes to take over or surrender the cargo is measurable and easily comparable to other competing seaports. A similar workflow applies in the reverse direction, i.e. in
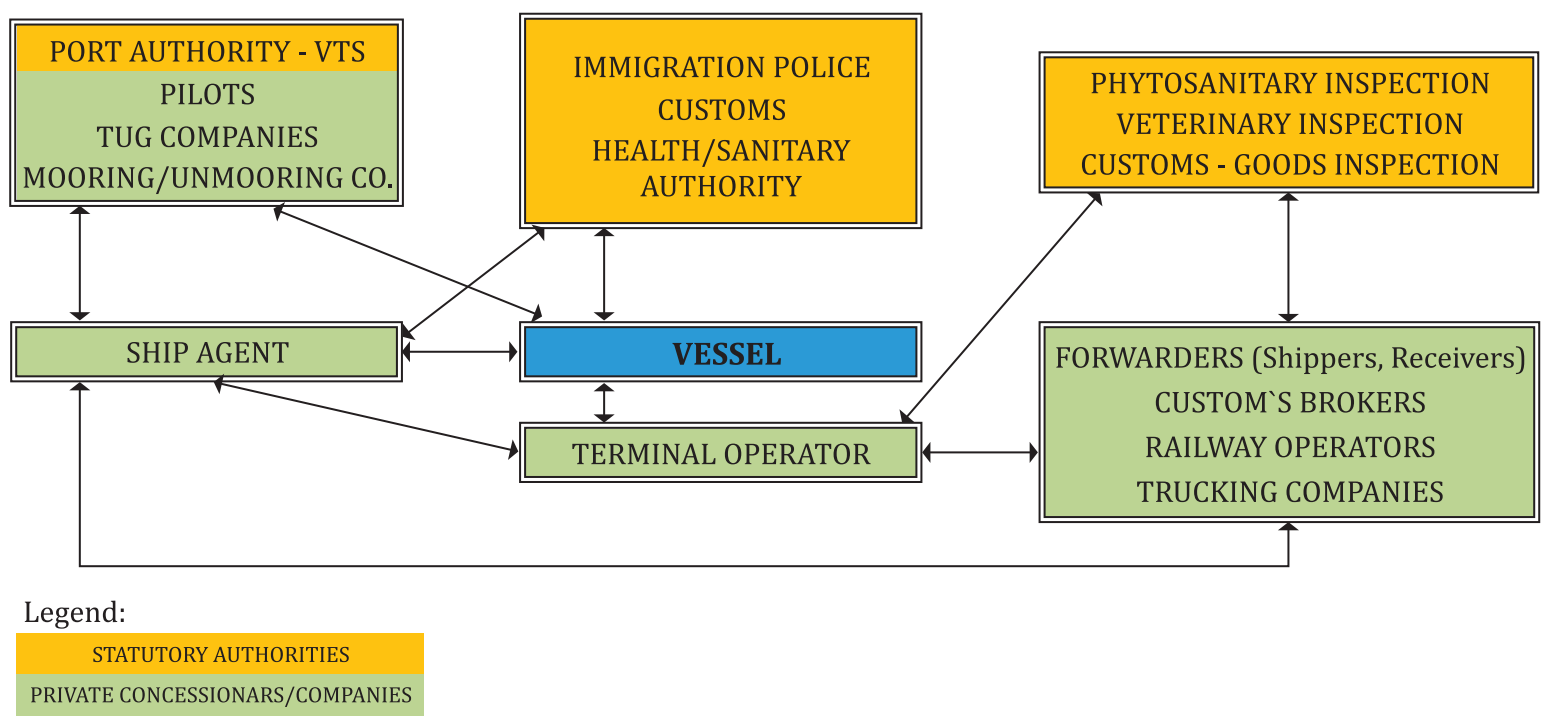

Figure 1 Seaport cluster stakeholders and communication flows 
the export business and departure of the vessel from the seaport.

It should be emphasized that the ship agent (as a representative of the ship owner and/or charterer - the Principal) brings together all the above mentioned parties, announces the prearrival and arrival of the ship to the port, coordinates the ship's arrival and departure clearances, orders the service of the port workers at the terminal, delivers all necessary cargo data to Customs, handles the invoicing and charging of freight rates, demurrage and detention charges, releases the cargo to the recipients or forwarders or receives cargo on behalf of the Principal from the shippers or forwarders, etc. In cases when the Principal offers its multimodal transport service (combining sea and inland transport on door to door basis), ship agent also serves as an inland transport organizer.

An important role of the ship agent is manifested in the creation of a pro-forma disbursement account, delivered to the Principal before the vessel arrives to the port. It is his obligation to secure pre-funding from the Principal to pay ship port costs before the vessel arrives. If deviations occur between the projected and actual costs incurred during the stay of the vessel in the port, and especially if they arise due to certain bottlenecks in the seaport cluster and the nontransparency in the tariff system of the service providers, it is thus more difficult to subsequently charge and collect from the Principal the resulting difference.

\section{Research Results}

In order to determine the harmonization of working hours between the mentioned stakeholders in the seaport cluster, a survey was carried out in the port of Rijeka, Croatia. Data was gathered and systematized on the duration of work shifts and breaks, the duration of regular and overtime work, and the additional overtime charges by some service providers (including Saturdays, Sundays and holidays). The questions were as follows:

- shift schedule (from-to) during weekdays (first, second or third shift if applicable)

- shift schedule (from-to) during Saturdays, Sundays and holidays (first, second or third shift if applicable)

- breaks for each shift (weekdays, Saturdays, Sundays, holidays)

- regular work time (from-to)

- overtime (from-to)

- overtime surcharges (if applicable).

After analysing the collected data, it was established that different service providers have differently organized working hours on different bases.

For example, the Harbour Master Office (Department of Maritime Traffic), Customs and Maritime Border Police work around-the-clock from 00:00 to 24:00, but have different shifts. The Harbour Master Office and the Customs operate in two shifts: from 07:00 to 19:00 and from 19:00 to 07:00. Maritime border police also operate in two shifts, but different, from $06: 00$ to $18: 00$ and from 18:00 to 06:00.
During the process of ships' arrival clearance, it is necessary to ensure simultaneous and timely presence of all the aforementioned stakeholders on board. In certain situations, when the shifts of different stakeholders are ending or beginning, it is not possible to ensure their simultaneous boarding and presence during the ship`s arrival clearance. Because of these situations, additional costs can occur due to waiting, both for the ship or port operators.

In the Harbour Master Office, the Inspection Department operates Monday to Friday from 07:00 to 15:00. Sometime it happens that certain tasks within their jurisdiction (e.g. deck cargo load control and lashing control) cannot be performed outside of that time period, which may cause the ship to wait.

The port operator provides a around-the-clock loading/unloading service organized in 3 shifts:

- 1 st shift from 06:30 to 14:30

- 2nd shift from 14:30 to 22:30

- 3rd shift from 22:30 to 06:30 (calculated as overtime during weekdays).

The additional fee for overtime work during the $3^{\text {rd }}$ shift, Saturdays, Sundays and holidays vary from $50 \%$ to $150 \%$ added to the basic tariff for regular working hours.

Border inspections that provide ship and cargo services (Sanitary inspection, Phytosanitary inspection and Veterinary inspection do not provide all-day service, and have different working hours:

- Sanitary Inspection from 08:00 to 16:00

- Phytosanitary Inspection from 07:00 to 15:00

- Veterinary Inspection from 07:00 to 19:00.

Private companies that provide around-the-clock ship service (pilots, tugs and mooring service) have harmonized working hours and harmonized shifts (from 08:00 to 20:00 and from 20:00 to 08:00), but have different views on regular or overtime work. Pilots and mooring service consider the timeframe from 06:00 to 22:00 to be regular work time, and the time frame from 22:00 to 06:00 to be overtime. On the other hand, tug service considers the timeframe from 05:00 to 22:00 to be regular work time, and the time frame from 22:00 to 05:00 to be overtime. Further analysis of the tariffs of the above-mentioned service providers shows a different application of overtime surcharge during the week and during Saturdays, Sundays and holidays, ranging from $25 \%$ to $100 \%$.

Because of the inconsistencies in determining the regular and overtime work, it may happen that different stakeholders who simultaneously perform a joint task will calculate their tariffs differently. For example, pilots and mooring company will charge overtime fees from 22:00 to 06:00, and tug service will charge overtime fees from 22:00 to 05:00. For the service performed between 05:00 and 06:00 the user will be charged for overtime service by the pilots and mooring service, but not by the tug service.

From the collected data, it is apparent that surcharges for overtime work can vary from $25 \%$ to $150 \%$ (added to the basic tariff). In seaport clusters, it is common practice 
to organize work in the so-called "turnovers" (12 hours work - 24 hours break - 12 hours work - 48 hours break). In such situations, overtime pay for workers is provided, and operations costs are anyhow the same in the regular and overtime work. The wide range of overtime surcharges (from $25 \%$ to $150 \%$ ) can definitely be narrowed, with an aim to reduce costs for end users and to increase competitiveness of the seaport cluster.

The railway operator provides around-the-clock service in two shifts from 07:00 to 19:00 and from 19:00 to 07:00. Harmonization between the rail operator and the port operator is necessary for numerous reasons, mainly because seaport business processes require simultaneous presence of both service providers. From the above mentioned, it is evident that the port operator operates in three shifts and the railway operator in two shifts, with different starting and ending times. Such mismatch may in certain circumstances cause queues and interruptions. In addition to the lack of shift coordination between the rail and the port operator, there is also a problem of nonmatching shift break times. Due to different time periods of shift breaks, it is sometimes difficult to ensure that different service providers are jointly available at the same time.

The Port Authority operates from 08:00 to $16: 00$, and the VTS service operates around-the-clock in 3 shifts.

Ship and cargo agents and forwarders normally operate on weekdays from 08:00 to 16:00. However, if the job requires (agency activities, cargo reception and shipping operations, customs operations etc.), they provide their services around-the-clock, based on end user requests.

From the analysis of working time of different stakeholders in the seaport cluster, the following general mismatches can be derived:

- Different starting/ending times and duration of shifts

- Different periods of regular and overtime work

- Different periods of shift breaks

- Different surcharge percentages for overtime work.

The authors here present and elaborate a hypothetical example - a situation that may arise due to different working hours of different stakeholders in the seaport cluster (based on real data):

- The ship arrives to anchorage (pilot station) at 05:00

- In order to avoid the overtime costs of tug service and mooring service, pilot service is ordered by the ship agent only at 06:00

- Port operator shift starts at 06:30

- The usual berthing procedure lasts approximately one hour, therefore the ship is expected to be moored at 7:00 am

- Due to the shift schedules of the Customs and Harbour Master Office (start at 07:00), all necessary representatives of the statutory authorities (Customs, Harbour Master Office and Maritime Border Police) can be expected to board the ship around 7:15

- If no objections are noted, the ship will be granted arrival clearance and start the commercial procedures (loading/discharging) around 08:00.
Although the ship arrived at anchorage at 05:00, due to attempts to avoid overtime costs of some operators and the different start of shifts of statutory authorities, the commercial operations started only at 08:00. In this example, a certain waiting time for the Port operator was noted (minimum of 30 minutes). Consequently, the productivity of the transhipment services was reduced, and the stay of the ship in the port was prolonged, creating additional costs for the vessel`s Operator.

In this (or similar) hypothetical example, a certain negative perception of availability, efficiency, reliability and overall quality of seaport services can be expected. Consequently, the competitiveness of the seaport cluster or the whole traffic route can be reduced.

\section{Discussion and Conclusions}

Based on the research of the working timetables of seaport cluster stakeholders, and the observed mismatches elaborated in the previous chapter, the authors suggest that it is necessary to ensure the harmonization of working hours of different stakeholders in the seaport cluster, as follows:

- To synchronize the working shifts of the stakeholders who operate around-the-clock, and whose joint presence is indispensable in working and technological processes. It is particularly important to align the working hours of the statutory authorities (Harbour Master's Office, Customs and Maritime Border Police), port and rail operators.

- To equalize periods of regular and overtime work during the week and on Saturdays, Sundays and holidays

- To equalize periods of work breaks

- To equalize overtime surcharges or supplements.

By harmonizing working hours, the following can be achieved:

- Simplicity and transparency of seaport cluster operations (especially important for calculating pro-forma disbursement account)

- Improved perception about the availability, efficiency and reliability of seaport cluster stakeholders

- Greater seaport cluster productivity (especially port and rail operator)

- Avoidance of hidden costs for end users

- Increased competitiveness of the seaport cluster and of the traffic route/corridor through a certain seaport.

Given the above mentioned bottlenecks that may arise in the sea port cluster due to the lack of stakeholder synchronization, the authors suggest that the analysis of stakeholder working timetables (and their compatibility and harmonization) is definitely one of the attributes for determining the overall quality and competitiveness of the seaport cluster .

Improving the quality and competitiveness of the seaport cluster is a persistent long-term business process. Its objectives should be the permanence of the overall quality and competitiveness of the port service, from the arrival to 
the departure of the ship in port, and including unloading, loading and warehousing of cargo, cargo inspection/control and delivering the cargo to end-recipients (or receiving the cargo from the Shipper).

Given the heterogeneity of stakeholders in the seaport cluster, it is necessary to identify a legal entity to research, analyse and implement measures to maintain overall quality and competitiveness, one of them being the measure to ensure the harmonization of working hours of all stakeholders who operate within the seaport cluster. The authors recommend that, in the case of Croatia, the above mentioned entity should be the Port Authority.

\section{References}

[1] Batur, T., Nikolić, J.: Measuring the Efficiency of Ports and Terminals, Naše more, 63(2), Dubrovnik, 2016, pp. 61-64.

[2] Bendeković, J., Jolić, A., Jolić, N.: Upravljanje kvalitetom lučkih usluga, Ekonomska misao i praksa, Zagreb, 2010, No. 1, pp. 85-104.

[3] Kolanović, I.: Temeljne dimenzije kvalitete lučke usluge, Pomorstvo, Vol. 21, No. 2, Rijeka, 2007, pp. 207-224.

[4] Review of Maritime Transport 2011, UNCTAD, New York and Geneva, 2011, p. 90.

[5] Zanne, M., Twrdy, E., Stojaković, M.: How dependent is the competitiveness of port of Koper on its railway connection, 6th IMSC, Solin, Croatia, April 2014, pp. 131-136. 